CASE REPORT

\title{
Sarcoidosis of the prostate
}

\section{Bungo Furusato, Stacey Koff, David G McLeod, Isabell A Sesterhenn}

J Clin Pathol 2007;60:325-336. doi: 10.1136/jcp.2006.039222

\begin{abstract}
A 55-year-old African-American man with clinical stage Tlc prostate cancer underwent prostatectomy. Non-caseating, epithelioid granulomata adjacent to the anterior fibromuscular stroma were found incidentally. The granulomata included Langhans giant cells with rare conchoidal bodies. The distribution of the granulomata was not that of non-specific granulomatous prostatitis centred around ducts and glands. By immunohistochemistry, the epithelioid cells were positive for angiotensin-converting enzyme. The histological appearance suggested sarcoidosis, which was confirmed by the clinical history. Four years earlier, the patient had been treated for sarcoidosis.
\end{abstract}

O nly four cases of prostatic sarcoidosis have been reported. ${ }^{1-4}$ Three of these patients had a known history of sarcoidosis. One of the patients had a prostate biopsy for a nodule. In addition to prostatic carcinoma, granulomata consistent with sarcoid were also found. ${ }^{3}$

Here, an additional case of sarcoidosis and carcinoma involving the prostate is reported.

\section{Case presentation}

A 55-year-old African-American man was found to have a prostate-specific antigen level of $6.53 \mathrm{ng} / \mathrm{ml}$ on screening. Digital rectal examination was unremarkable.

The patient underwent 10 cores transrectal ultrasoundguided biopsies, which showed a prostatic adenocarcinoma with a Gleason Score of $5+3=8$. The clinical stage was Tlc and the patient underwent prostatectomy in January 2003.

The radical prostatectomy contained seven foci of adenocarcinoma with a Gleason Score of 3 and 4 in the largest tumour. The pathological stage was T3a.



Figure 1 Non-caseating, epithelioid granulomata in anterior fibromuscular stroma $(\mathrm{H} \& \mathrm{E}, \times 40)$. Inset, angiotensin-converting enzyme (ACE) positive in epithelioid histiocytes (anti-ACE, $\times 160$ ).
The unusual finding was a group of non-caseating, epithelioid granulomata adjacent to the anterior fibromuscular stroma and to one of the tumours (fig 1). The granulomata included Langhans-type giant cells, one of which contained a calcified conchoidal (Schaumann) body. By immunohistochemistry, the epithelioid cells were positive for angiotensinconverting enzyme (fig 1, inset). The distribution of the granulomata was not that of non-specific granulomatous prostatitis where the granulomas are centred around the ducts and glands. No necrosis was found that would suggest a granulomatous inflammation owing to microorganisms. The distinctive appearance of the post-transurethral resection granuloma was not seen. The histological appearance suggested sarcoidosis. Additional clinical information indicated that the patient had been treated for sarcoidosis 4 years earlier.

\section{DISCUSSION}

Sarcoidosis rarely involves the prostate (table 1).

In 1936, Schauman ${ }^{1}$ reported the first case of prostatic sarcoidosis in a patient with disseminated disease. In a review of 300 cases, including 22 autopsies, Ricker and Clark ${ }^{4}$ found only one case with prostatic involvement. Morris et $a l^{2}$ treated one patient with known sarcoidosis for "penile pain and reduced ejaculatory volume". The biopsy specimen of the prostate showed numerous granulomata. Todd and Garnick ${ }^{3}$ reported a patient with known dermal sarcoidosis, who also had prostate involvement and prostatic carcinoma.

Except for the case described by Morris et $a l^{2}$, none of the patients had symptoms referable to the prostate. The diagnosis was made either at autopsy or incidentally at prostatectomy for cancer. In a review of patients with pulmonary and/or hilar lymph node sarcoidosis associated with malignant tumours, Brincker and Wilbek ${ }^{5}$ described one patient with concomitant prostatic carcinoma but no mention was made of prostatic sarcoid. In our patient, the presence of non-caseating, epithelioid granulomata not associated with the glandular elements or necrosis led us to consider sarcoidosis. A detailed medical history confirmed this suspicion. The diagnosis was made through transbronchial biopsy more than 4 years earlier when the patient presented with brachial plexopathy and pulmonary symptoms. The patient had been treated with a course of steroids. Considering the rarity of prostatic sarcoidosis, this diagnosis is usually not entertained. A detailed clinical history, radiological imaging studies, cultures and appropriate histological investigation to exclude other entities are necessary for the correct diagnosis.

Table 1 Cases of sarcoidosis in prostate

\begin{tabular}{|c|c|c|c|c|c|}
\hline Authors & Year & $\begin{array}{l}\text { Number } \\
\text { of cases }\end{array}$ & $\begin{array}{l}\text { Age } \\
\text { (years) }\end{array}$ & $\begin{array}{l}\text { History of } \\
\text { sarcoidosis }\end{array}$ & $\begin{array}{l}\text { Type of } \\
\text { specimen }\end{array}$ \\
\hline $\begin{array}{l}\text { Schaumann } \\
\text { Ricker and Clark } \\
\text { Todd and Garnick } \\
\text { Morris et af } \\
\text { This study } \\
\text { Prostatectomy }\end{array}$ & $\begin{array}{l}1936 \\
1949 \\
1980 \\
1993 \\
2006\end{array}$ & $\begin{array}{l}1 / 2 \\
1 / 21 \\
1 \\
1 \\
1\end{array}$ & $\begin{array}{l}42 \\
25 \\
78 \\
28 \\
55\end{array}$ & $\begin{array}{l}\text { Yes } \\
\text { Yes } \\
\text { Yes } \\
\text { Suspicious } \\
\text { Not known* }\end{array}$ & $\begin{array}{l}\text { Autopsy } \\
\text { Autopsy } \\
\text { Biopsy } \\
\text { Biopsy }\end{array}$ \\
\hline
\end{tabular}

*Not known at the time of prostatectomy. 


\author{
Authors' affiliations \\ Bungo Furusato, Isabell A Sesterhenn, Department of Genitourinary \\ Pathology, Armed Forces Institute of Pathology, Washington, DC, USA \\ Stacey Koff, David G McLeod, Urology Services, Walter Reed Army \\ Medical Center, Washington, DC, USA \\ Competing interests:None
}

Correspondence to: $\mathrm{Dr} I \mathrm{~A}$ Sesterhenn, Armed Forces Institute of Pathology, 6825 16th Street NW, Bldg 54, PB13, Washington, DC 203066000, USA; sesterhe@afip.osd.mil

Accepted 25 April 2006

\section{REFERENCES}

1 Schaumann J. Lymphogranulomatosis benigna in the light of prolonged clinical observations and autopsy findings. Br J Derm Syph 1936:48:399-446.

2 Morris SB, Gordon EM, Corbishley CM. Prostatic sarcoidosis. Review of genitourinary sarcoidosis. Br J Urol 1993;72:462-4.

3 Todd RF III, Garnick MB. Prostatic adenocarcinoma, sarcoidosis and hypercalcemia: an unusual association. J Urol 1980;123:133-4.

4 Ricker W, Clark M. Sarcoidosis. A clinicopathological review of three hundred cases including twenty-two autopsies. Am J Clin Pathol 1949:19:725-49.

5 Brincker $\mathrm{H}$, Wilbek $\mathrm{E}$. The incidence of malignant tumours in patients with respiratory sarcoidosis. Br J Cancer 1974;29:247-51.

\section{Cervical embryonal rhabdomyosarcoma and ovarian Sertoli- Leydig cell tumour: a more than coincidental association of two rare neoplasms?}

\section{Gareth E McClean, Susy Kurian, Noel Walter, A Kekre, W Glenn McCluggage}

J Clin Pathol 2007;60:326-328. doi: 10.1136/icp.2006.039206

A case in which an embryonal rhabdomyosarcoma of the cervix and an ovarian Sertoli-Leydig cell tumour of intermediate differentiation occurred in a 13-year-old girl is described. Although initially considered as a chance association, a review of the literature showed the co-occurrence of these two uncommon neoplasms in three previous cases. The reason for this association, which is thought to be more than coincidental, is not known, although an underlying genetic abnormality is a possibility. The ovarian tumour in this case was characterised by the presence of foci of cells with extremely pleomorphic nuclei, which initially raised the possibility of metastatic rhabdomyosarcoma. These were interpreted as foci of bizarre nuclei within the Sertoli-Leydig cell tumour.

W hen two or more neoplasms occur in the same patient, this is generally a chance association. However, when two rare tumours coexist, the question of an association that is more than coincidental is raised. For instance, the occurrence of gastric epithelioid leiomyosarcoma (now redesignated as a gastrointestinal stromal tumour), pulmonary chondroma and extra-adrenal paraganglioma in several patients resulted in the description of Carney triad. ${ }^{12}$ In this report, we describe the coexistence of a cervical embryonal rhabdomyosarcoma and an ovarian Sertoli-Leydig cell tumour in a 13-year-old girl. Although we initially considered this as a chance association, a review of the published literature showed three other similar reported cases, ${ }^{3}{ }^{4}$ strongly suggesting a more than coincidental association between these two uncommon neoplasms. The basis for the association is not clear, but in highlighting this we speculate on possible reasons.

\section{CASE REPORT}

A 13-year-old Indian girl with no previous medical problems presented with mild hirsutism and change in voice. Menarche was at the age of 12 years, and this was followed by a period of amenorrhoea for 9 months. She was found to have a cervical polyp, which was avulsed. Subsequent radiological investigations performed immediately after the histological diagnosis rendered on the cervical polyp showed a mass in the right ovary measuring $4 \mathrm{~cm}$ in maximum dimension. Right salpingo-oophorectomy was performed. The case is recent and we have no significant follow-up.

\section{PATHOLOGICAL FINDINGS}

The cervical polyp measured $3 \mathrm{~cm}$ in maximum dimension. Histological examination showed benign endocervical glands on the surface and within the substance of the lesion. The stroma had a myxoid appearance with an increased cellularity around the glands resulting in a cambium layer (fig 1). The cellular component of the stroma was composed of regular spindle cells with hyperchromatic nuclei and easily identifiable mitotic figures (in areas 1-2 per high power field) within the cambium layer (fig 2). Classical rhabdomyoblasts with cross-striations were not identified. No cartilaginous elements were seen. The stromal spindle shaped cells stained focally positive with desmin, and exhibited focal nuclear positivity with myogenin. A diagnosis of embryonal rhabdomyosarcoma was made.

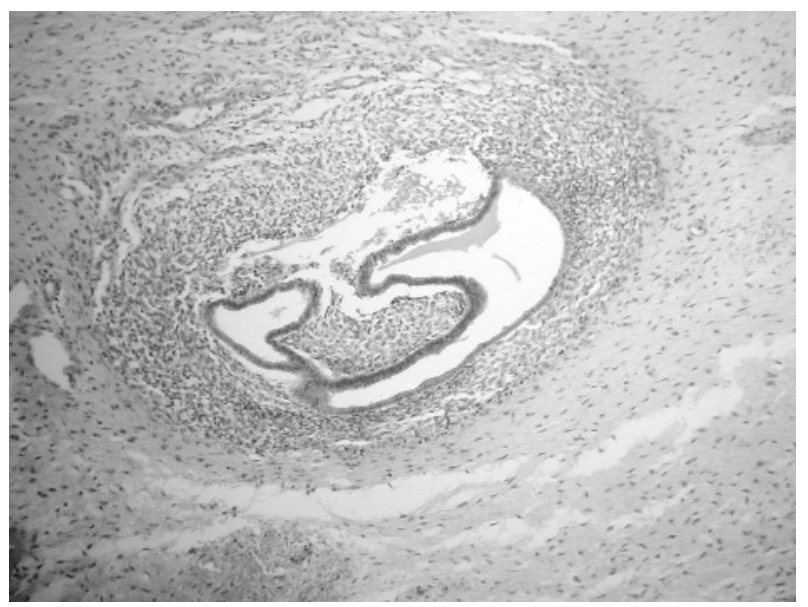

Figure 1 Cervical embryonal rhabdomyosarcoma where stromal cells condense around glandular elements forming a cambium layer. 